\title{
EDITORIAL
}

\section{PROPOSAL FOR A RATIONAL CLASSIFICATION OF NECK DISSECTIONS}

Alfio Ferlito, MD, DLO, DPath, FRCSEd ad hominem, FRCS (Eng, Glasg, Ir) ad eundem, FDSRCS ad eundem, FHKCORL, FRCPath, FASCP, IFCAP, ${ }^{1} \mathrm{~K}$. Thomas Robbins, MD, FRCSC, ${ }^{2}$ Jatin P. Shah, MD, PhD (Hon), MS, FRCSEd (Hon), FRACS (Hon), FDSRCS, ${ }^{3}$ Jesus E. Medina, MD, ${ }^{4}$ Carl E. Silver, MD, ${ }^{5}$ Shawkat Al-Tamimi, MD, ${ }^{6}$ Johannes J. Fagan, MBChB, FCS (SA) MMed, ${ }^{7}$ Vinidh Paleri, MS, FRCS (ORL-HNS), ${ }^{8}$ Robert P. Takes, MD, PhD, ${ }^{9}$

Carol R. Bradford, MD, ${ }^{10}$ Kenneth O. Devaney, MD, JD, FCAP, ${ }^{11}$ Sandro J. Stoeckli, MD, ${ }^{12}$

Randal S. Weber, MD, ${ }^{13}$ Patrick J. Bradley, MB, BCh, BAO, DCH, MBA, FRCS (Ed, Eng, Ir),

FHKCORL, FRCSLT (Hon), FRACS (Hon) ${ }^{14}$ Carlos Suárez, MD, PhD, ${ }^{15,16}$

C. René Leemans, MD, PhD, ${ }^{17}$ H. Hakan Coskun, MD, ${ }^{18}$ Karen T. Pitman, MD, ${ }^{19}$

Ashok R. Shaha, MD, ${ }^{3}$ Remco de Bree, MD, PhD, ${ }^{17}$ Dana M. Hartl, MD, PhD, ${ }^{20,21}$

Missak Haigentz, Jr, MD, ${ }^{22}$ Juan P. Rodrigo, MD, PhD, ${ }^{15,16}$ Marc Hamoir, MD, ${ }^{23}$ Avi Khafif, MD, ${ }^{24}$

Johannes A. Langendijk, MD, PhD, ${ }^{25}$ Randall P. Owen, MD, MS, ${ }^{26}$

Alvaro Sanabria, MD, MSc, $\mathrm{PhD},{ }^{27}$ Primož Strojan, MD, $\mathrm{PhD},{ }^{28}$

Vincent Vander Poorten, MD, PhD, ${ }^{29}$ Jochen A. Werner, MD, ${ }^{30}$

Stanisław Bień, MD, PhD, ${ }^{31}$ Julia A. Woolgar, FRCPath, PhD, ${ }^{32}$ Peter Zbären, MD, ${ }^{33}$

Jan Betka, MD, PhD, FCMA, ${ }^{34}$ Benedikt J. Folz, MD, ${ }^{35}$ Eric M. Genden, MD, ${ }^{36}$

Yoav P. Talmi, MD, ${ }^{37}$ Marshall Strome, MD, MS, ${ }^{38}$ Jesús Herranz González Botas, MD, ${ }^{39}$

Jan Olofsson, MD, ${ }^{40}$ Luiz P. Kowalski, MD, PhD, ${ }^{41}$ Jon D. Holmes, DMD, MD, ${ }^{42}$

Yasuo Hisa, MD, PhD, ${ }^{43}$ Alessandra Rinaldo, MD, FRCSEd ad hominem, FRCS (Eng, Ir) ad eundem, FRCSGlasg ${ }^{1}$

${ }^{1}$ Department of Surgical Sciences, ENT Clinic, University of Udine, Udine, Italy. E-mail: a.ferlito@uniud.it

${ }^{2}$ Division of Otolaryngology-Head and Neck Surgery, Southern Illinois University School of Medicine,

Springfield, Illinois

${ }^{3}$ Head and Neck Service, Memorial Sloan-Kettering Cancer Center, New York, New York

${ }^{4}$ Department of Otorhinolaryngology, The University of Oklahoma Health Sciences Center, Oklahoma City, Oklahoma

${ }^{5}$ Departments of Surgery and Otolaryngology-Head and Neck Surgery, Albert Einstein College of Medicine,

Montefiore Medical Center, Bronx, New York

${ }^{6}$ Department of Otolaryngology-Head and Neck Surgery, King Hussein Medical Center, Royal Medical

Services, Amman, Jordan

${ }^{7}$ Division of Otolaryngology, Faculty of Health Sciences, University of Cape Town, Cape Town, South Africa

Correspondence to: A. Ferlito

This paper was written by members and invitees of the International

Head and Neck Scientific Group.

(C) 2010 Wiley Periodicals, Inc. 
${ }^{8}$ Department of Otolaryngology-Head and Neck Surgery, Newcastle upon Tyne Foundation Hospitals NHS Trust, Newcastle upon Tyne, United Kingdom

${ }^{9}$ Department of Otolaryngology-Head and Neck Surgery, Radboud University Nijmegen Medical Center, Nijmegen, The Netherlands

${ }^{10}$ Department of Otolaryngology-Head and Neck Surgery, University of Michigan, Ann Arbor, Michigan

${ }^{11}$ Department of Pathology, Allegiance Health, Jackson, Michigan

${ }^{12}$ Department of Otorhinolaryngology-Head and Neck Surgery, Kantonsspital, St. Gallen, Switzerland

${ }^{13}$ Department of Head and Neck Surgery, The University of Texas MD Anderson Cancer Center, Houston, Texas

${ }^{14}$ Department of Otorhinolaryngology-Head and Neck Surgery, Nottingham University Hospitals,

Queens Medical Centre Campus, Nottingham, United Kingdom

${ }^{15}$ Department of Otolaryngology, Hospital Universitario Central de Asturias, Oviedo, Spain

${ }^{16}$ Instituto Universitario de Oncología del Principado de Asturias, Oviedo, Spain

${ }^{17}$ Department of Otolaryngology-Head and Neck Surgery, VU University Medical Center, Amsterdam,

The Netherlands

${ }^{18}$ Department of Otolaryngology-Head and Neck Surgery, Uludag University School of Medicine, Bursa, Turkey

${ }^{19}$ Department of Otolaryngology and Communicative Sciences, University of Mississippi Medical Center, Jackson, Mississippi

${ }^{20}$ Department of Otolaryngology-Head and Neck Surgery, Institut Gustave Roussy, Villejuif Cedex, France

${ }^{21}$ Laboratoire de Phonétique et de Phonologie, Sorbonne Nouvelle, Paris, France

${ }^{22}$ Department of Medicine, Division of Oncology, Albert Einstein College of Medicine, Montefiore Medical

Center, Bronx, New York

${ }^{23}$ Department of Head and Neck Surgery, Head and Neck Oncology Program, St Luc University Hospital and Cancer Center, Brussels, Belgium

${ }^{24}$ Head and Neck Surgery and Oncology Unit, A.R.M. Center for Advanced Otolaryngology-Head and Neck

Surgery, Assuta Medical Center, Tel Aviv, Israel

${ }^{25}$ Department of Radiation Oncology, University Medical Center Groningen, University of Groningen, Groningen, The Netherlands

${ }^{26}$ Department of Surgery, Division of Metabolic, Endocrine and Minimally Invasive Surgery, Mount Sinai

School of Medicine, New York, New York

${ }^{27}$ Department of Surgery, Universidad de La Sabana-Fundacion Abood Shaio, Bogota, Colombia

${ }^{28}$ Department of Radiation Oncology, Institute of Oncology, Ljubljana, Slovenia

${ }^{29}$ Department of Otorhinolaryngology-Head and Neck Surgery, University Hospitals Leuven, Leuven, Belgium

${ }^{30}$ Department of Otolaryngology-Head and Neck Surgery, Philipp University, Marburg, Germany

${ }^{31}$ Department of Otolaryngology-Head and Neck Surgery, Holy Cross Cancer Centre, Kielce, Poland

${ }^{32}$ Oral Pathology, University of Liverpool Dental Hospital, Liverpool, United Kingdom

${ }^{33}$ Department of Otorhinolaryngology-Head and Neck Surgery, University Hospital, Berne, Switzerland

${ }^{34}$ Department of Otorhinolaryngology-Head and Neck Surgery, 1st Faculty of Medicine, Faculty Hospital

Motol, Charles University, Prague, Czech Republic

${ }^{35}$ Department of Otorhinolaryngology-Head and Neck Surgery, Karl Hansen Medical Center, Bad

Lippspringe, Germany

${ }^{36}$ Department of Otolaryngology-Head and Neck Surgery, The Mount Sinai Medical Center, New York, New York

${ }^{37}$ Head and Neck Service, The Chaim Sheba Medical Center, Tel Hashomer and Tel Aviv University Sackler

School of Medicine, Tel Aviv, Israel

${ }^{38}$ Department of Otolaryngology and Communicative Disorders, Cleveland Clinic Head and Neck Institute, Cleveland, Ohio

${ }^{39}$ Department of Otorhinolaryngology, University Hospital A Coruña, A Coruña, Spain

${ }^{40}$ Department of Otolaryngology-Head and Neck Surgery, Haukeland University Hospital, Bergen, Norway

${ }^{41}$ Department Otorhinolaryngology-Head and Neck Surgery, Centro de Tratamento e Pesquisa Hospital do Cancer A.C. Camargo, São Paulo, Brazil

${ }^{42}$ Department of Oral and Maxillofacial Surgery, University of Alabama at Birmingham, Birmingham, Alabama

${ }^{43}$ Department of Otolaryngology-Head and Neck Surgery, Kyoto Prefectural University of Medicine, Kyoto, Japan

Accepted 12 August 2010

Published online in Wiley Online Library (wileyonlinelibrary.com). DOI: 10.1002/hed.21614 
It is important to have an internationally recognized, precise nomenclature for different types of neck dissection both for clinical and research purposes. However, as neck dissection techniques have evolved, previously described nomenclature of neck dissections have become confusing and less used globally. This lack of international acceptance of a uniform classification, and the increasing use of more limited lymphadenectomy procedures, prompted this re-evaluation of neck dissection classifications, and suggestion of a new system of terminology.

Evolution of Neck Dissection. Neck dissection has evolved into a variety of surgical procedures for excision of regional lymph nodes since its introduction in the 19th century, when surgeons first became aware that cancers of the head and neck metastasized to the cervical lymph nodes. Surgical lymphadenectomy was first described in the late $1800 \mathrm{~s}$ by surgeons such as Kocher, Billroth, von Langenbeck, and von Volkmann, who explored removal of portions of lymph node-bearing tissue. ${ }^{1}$ Initial attempts at surgical removal of neck metastases were disastrous. However, Jawdyński ${ }^{2}$ in 1888 described in great detail his first successful radical en bloc resection of a metastatic mass in the neck. Later in 1905, Crile ${ }^{3}$ reported his experience using this systematic en bloc approach for excision of cervical lymph nodes and documented its efficacy in a large series of patients. Martin et $\mathrm{al}^{4}$ also reported the efficacy of classical radical neck dissection based on a large series of patients, and recommended the operation both in an elective setting and as a therapeutic procedure. Starting in 1952, Suárez began to employ a modified technique by preserving nonlymphatic structures. ${ }^{5}$ He named this procedure the "functional" or "conservative" neck dissection, which was later promoted by Bocca $^{6}$ and Gavilán et al. $^{7}$ In the $1960 \mathrm{~s}$, Ballantyne and the surgeons at MD Anderson Cancer Institute introduced the concept of dissecting only the lymph nodes most at risk of containing metastases, depending upon the location of the primary tumor. 8

The advent of chemoradiation as the initial definitive treatment for squamous cell carcinoma of many primary sites during the late 20th and early 21st century has enabled the use of other variations of neck dissection, as a valid pathological basis for performing less extensive procedures has been established.
At the present time, a variety of new modifications of neck dissection, in which only groups of lymph nodes considered at risk are removed, have been shown to be oncologically, functionally, and cosmetically effective for prophylactic or therapeutic treatment of the neck. These procedures have been termed selective, extended selective, and superselective neck dissections, all of which have been applied as either part of the initial phase of treatment or after chemoradiation. ${ }^{9-12}$

Neck Dissection Terminology. With a variety of modifications of neck dissection techniques reported in the literature, a varied and often confusing nomenclature has evolved. These names have usually been based on the extent or limitation, and intent or purpose of the neck dissection.

Myriad terms are and have been used for neck dissection procedures which extirpate all the nodes in levels I to V. This list includes radical neck dissection, modified radical neck dissection, modified neck dissection types I to III, modified comprehensive neck dissection types I to III, extended radical neck dissection, radical en bloc neck dissection, extended radical en bloc neck dissection, conventional radical neck dissection, classical radical neck dissection, conservative neck dissection, complete functional neck dissection, nerve-sparing radical neck dissection, nerve/muscle-sparing radical neck dissection, nerve/muscle/vein-sparing radical neck dissection, and total neck dissection.

For more limited neck dissection procedures, numerous terms have also been used, including selective, extended selective, superselective, suprahyoid, supraomohyoid, extended supraomohyoid, jugular node, lateral neck, posterolateral, anterior, anterolateral, regional, minor, limited, upper-lateral, lower, lower-lateral neck dissections, and many others. Additional terms that have been used are fascial neck dissection, precautional neck dissection, Suárez neck dissection, Bocca neck dissection, modified neck dissection, and cervical lymphadenectomy.

Terms based on the intent or purpose of the neck dissection include planned neck dissection, therapeutic neck dissection, elective neck dissection, prophylactic neck dissection, salvage neck dissection, and others, depending on the vocabulary and imagination of the surgeon.

Classification of Neck Dissections. The need to standardize the nomenclature relating to neck dissections is critical and self-apparent. In 1987, 
Suen and Goepfert ${ }^{13}$ were among the first to suggest a universally acceptable classification of neck dissections, which was simplified 2 years later by Medina. ${ }^{14}$ The principle behind both classifications was to identify 3 broad categories of neck dissection: standard radical neck dissection, comprehensive modified radical neck dissection, and selective neck dissection.

In 1991, the Committee for Head and Neck Surgery and Oncology of the American Academy of Otolaryngology-Head and Neck Surgery, in conjunction with the Education Committee of the American Society for Head and Neck Surgery (ASHNS), ${ }^{15}$ proposed a classification system which was revised in $2002 .{ }^{16}$ In 2008 , the Committee for Neck Dissection Classification of the American Head Neck Society (AHNS) published an update. ${ }^{17}$ This classification is based on 4 basic procedures:

1. Radical neck dissection is the standard basic procedure for cervical lymphadenectomy which includes removal of lymph nodes from levels I to V, with removal of the sternocleidomastoid muscle, the spinal accessory nerve, and the internal jugular vein (the removal of the submandibular gland is implied).

2. Modified radical neck dissection involves removal of lymph nodes from levels I to V (as in radical neck dissection), but with the preservation of at least 1 of the nonlymphatic structures (ie, sternocleidomastoid muscle, spinal accessory nerve, and/or internal jugular vein).

3. Extended neck dissection refers to removal of additional lymph node levels or groups, and/or nonlymphatic structures (eg, muscle, blood vessel, nerve) not normally removed with a radical neck dissection. Examples of additional lymph node groups include superior mediastinal, parapharyngeal, retropharyngeal, periparotid, postauricular, suboccipital, and buccinator. Examples of other nonlymphatic structures are the external carotid artery, hypoglossal, and vagus nerves, and other neural, osseous, cutaneous, muscular, or vascular structures that are potentially involved with tumor or damaged by previous therapy.

4. Selective neck dissection refers to preservation of 1 or more lymph node levels. There are several variations of the selective neck dissection, some of which have traditionally been given specific names (eg, lateral, supraomohyoid, extended supraomohyoid, posterior or central, in addition to others).
In 1997, Pellitteri et $\mathrm{al}^{18}$ reported that the spinal accessory nerve, internal jugular vein, and sternocleidomastoid muscle were preserved in the majority of selective neck dissections, and that of those 3 structures, the internal jugular vein was most likely to be sacrificed. In 2010, Hamoir et $\mathrm{al}^{12}$ introduced the term "extended selective neck dissection" for when nonlymphatic structures such as the internal jugular vein, spinal accessory nerve, and/or the sternocleidomastoid muscle are removed in addition to selected lymph node levels.

The term "comprehensive" neck dissection encompasses the radical, modified radical, and extended neck dissections, in which all lymph nodes in levels I to $\mathrm{V}$ are removed. The terms "classical," "elective," or "prophylactic" neck dissection were proposed by Conley and von Fraenkel. ${ }^{19}$

Terms such as "functional," "conservative," and "limited" neck dissection are imprecise and are primarily nondescriptive. ${ }^{14}$ "Functional" neck dissection refers to the modified radical neck dissection type III. ${ }^{5,20}$ The term "functional" neck dissection is less precise, but has been used so extensively in the literature that these 2 terms may be considered synonymous. Medina ${ }^{14}$ recognized a subcategory of radical or comprehensive modified neck dissection in which level I is not included. These operations can be simply distinguished from their counterparts in which level I nodes are removed by designating them as subtype $\mathrm{A}$ (I-V lymph node groups) and subtype B (II-V lymph node groups), respectively. "Conservative" neck dissection usually refers to the same procedure ${ }^{21}$ but the term should be avoided because of its lack of precision. Similarly, the term "limited" neck dissection proposed by Turkula and Woods ${ }^{22}$ is imprecise.

Subclassification into "therapeutic" and "elective" neck dissection refers to the indication for surgery, but does not specify the extent of the dissection. "Therapeutic" neck dissection is used when cervical metastases are detected preoperatively. "Prophylactic" or preferably "elective" neck dissection is used when neck dissection is done for potential subclinical cervical metastases.

In 2005, the Japan Neck Dissection Study Group proposed a different classification system for neck dissections, ${ }^{23}$ published by the Japan Society of Clinical Oncology, and based on the classification of regional lymph nodes used in Japan. ${ }^{24}$ This system divides the cervical lymph nodes into 3 basic regions with subregions in each. The basic regions are designated by letters $\mathrm{S}$ (submental-submandibular), J (jugular), and $\mathrm{P}$ 
(posterior triangle). The 2 components of the dissected region ( $\mathrm{S}, \mathrm{J}$, and $\mathrm{P})$ and resected nonlymphatic tissue $(\mathrm{N}=$ spinal accessory nerve, $\mathrm{V}$ = internal jugular vein, and $\mathrm{M}=$ sternocleidomastoid muscle) are described in simplified form with parentheses, and with a slash (/) to distinguish between them. Commas (,) are used to separate lymphatic tissue and nonlymphatic tissue from other lymph node groups and nonlymphatic tissue. For example, ND (SJP/VNM) denotes "radical neck dissection"; ND (J, pt) denotes "selective neck dissection (II-IV, VI)". The subregions are identified by numbers after each letter (S1, S2, J1, J2, J3, P1, and P2), similar to the additional classification proposed by the AHNS for levels and sublevels IA, IB, IIA, IIB, III, IV, VA, and VB. Other lymph node zones are designated by the use of 2 lower-case letters $(\mathrm{eg}, \mathrm{sm}=$ superior mediastinal, $\mathrm{pt}=$ paratracheal, and $\mathrm{pg}=$ parotid gland). The problem with incorporating this system into general usage is that the terminology used, along with the symbols, are entirely different from those commonly in use throughout the Western world. The majority of American and European surgeons would not adopt this completely unfamiliar system.

Recommended Classification of Neck Dissections. In order to facilitate interinstitutional communication in the world, there is a compelling need to agree on an international nomenclature for cervical nodal groups and neck dissections, which is logical, unambiguous, precise, and easy to remember.

The classification for cervical lymph node groups proposed by Robbins et $\mathrm{al}^{17}$ in 2008 is simple, clear, well established, and easily understood by surgeons, oncologists, and diagnostic radiologists. It describes 7 levels and has precise clinical and image-based anatomic landmarks. These lymph node levels and sublevels are outlined in Figure 1.

To avoid confusion, redundancy, and misinterpretation among head and neck surgeons, we propose that neck dissection be classified as follows:

1. The symbol "ND" should be used to represent the term neck dissection and applied as the first component of the description. A prefix should be included to denote the side of the neck upon which the dissection has been performed using the abbreviation L for left, and $\mathrm{R}$ for right. If bilateral, both sides must be classified independently.

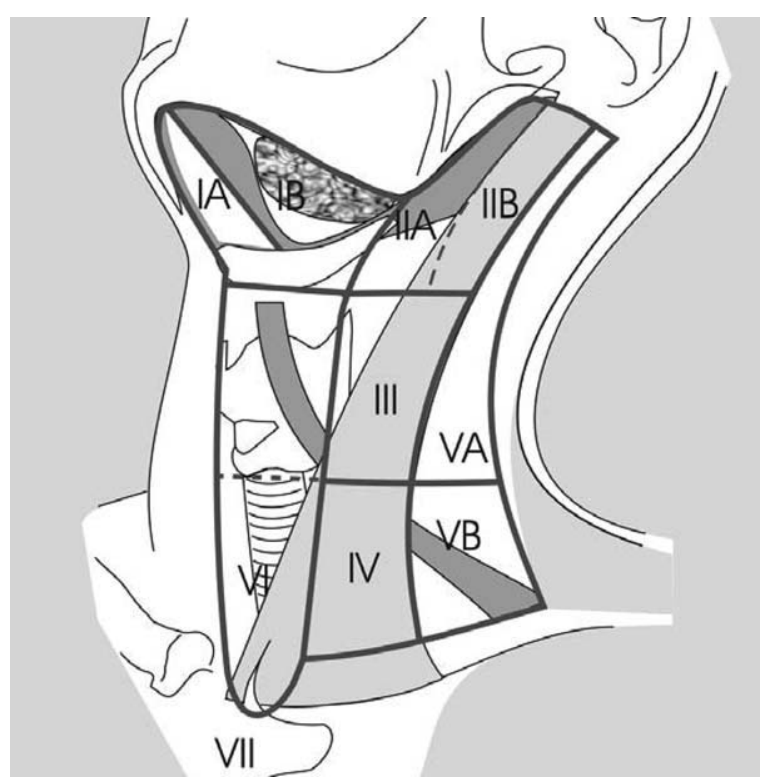

FIGURE 1. Lymph nodes levels and sublevels of the neck. ${ }^{17}$ Reproduced with permission from the Archives of Otolaryngology Head and Neck Surgery 134(5)536-538, 2008. Copyright (c) 2008 Amercian Medical Association. All rights reserved.

2. The second component of the description should be the neck levels and/or sublevels removed, each designated by the Roman numerals I through VII, in ascending order. For levels in which subdivision is applicable (such as I, II, V) the level is stated without a subdivision to indicate that the entire level (both A and B) was cleared. If a sublevel is named, it means that the remaining sublevel was preserved.

3 . The third component of the description should be the nonlymphatic structures removed, each identified through the use of specified acronyms (symbols), all of which have been universally accepted (Table 1).

This classification is logical, simple, and easy to remember, and conveys precisely the extent of the lymphatic and nonlymphatic structures removed in a neck dissection. It prevents possible confusion associated with ambiguous terminology previously mentioned. Importantly, it allows recording of neck dissection procedures that cannot be classified under the existing systems (Table 1). The categorical nature of the elements in the classification has the added advantage of lending itself to easy recording and analysis in large databases. With regard to quality analysis, the proposed classification system offers a more precise description of the surgical procedure. Therefore, it would appear that 
Table 1. Comparison of the new proposed terminology with the current widely used American terminology for different types of neck dissections. This demonstrates examples of neck dissection modifications currently practiced, which cannot be classified by the existing terminologies.

\begin{tabular}{|c|c|}
\hline Proposed nomenclature & $\begin{array}{c}\text { Nomenclature recommended } \\
\text { by AAO-HNS/AHNS }\end{array}$ \\
\hline ND (I-V, SCM, IJV, CN XI) & Radical neck dissection \\
\hline $\begin{array}{l}\text { ND (I-V, SCM, IJV, CN XI, } \\
\text { and CN XII) }\end{array}$ & $\begin{array}{l}\text { Extended neck dissection } \\
\text { with removal of the } \\
\text { hypoglossal nerve }\end{array}$ \\
\hline ND (I-V, SCM, IJV) & $\begin{array}{l}\text { Modified radical neck } \\
\text { dissection with preservation } \\
\text { of the spinal accessory nerve }\end{array}$ \\
\hline ND (II-IV) & $\begin{array}{l}\text { Selective neck dissection } \\
\quad(\text { II-IV) }\end{array}$ \\
\hline ND (II-IV, VI) & $\begin{array}{l}\text { Selective neck dissection } \\
\quad(I I-I V, V I)\end{array}$ \\
\hline ND (II-IV, SCM) & NA \\
\hline ND (I-III) & Selective neck dissection (I-III) \\
\hline $\begin{array}{l}\text { ND (I-III, SCM, IJV, } \\
\text { CN XI) }\end{array}$ & NA \\
\hline ND (II, III) & Selective neck dissection (II, III) \\
\hline$N D(I I A, I I I)$ & Selective neck dissection (IIA, III) \\
\hline ND (VI) & Selective neck dissection (VI) \\
\hline $\mathrm{ND}(\mathrm{VI}, \mathrm{VII})$ & Selective neck dissection (VI, VII) \\
\hline
\end{tabular}

Abbreviations: AAO-HNS, American Academy of Otolaryngology-Head and Neck Surgery; AHNS. American Head and Neck Society; ND, neck dissection; SCM, sternocleidomastoid muscle; IJV, internal jugular vein; CN XII, hypoglossal nerve; CN XI, spinal accessory nerve; NA, not available.

Note: Other suggested acronyms: SAN, spinal accessory nerve: ECA external carotid artery; ICA, internal carotid artery; CCA, common carotid artery; CN VII, facial nerve; $C N X$, vagus nerve; $S N$, sympathetic nerve chain; PN, phrenic nerve; SKN, skin; PG, parotid gland; SG, submandibular gland; DCM, deep cervical muscles.

such an improvement would translate into an improved ability to compare treatment outcomes among studies. With regard to procedure coding and billing, such changes in the nomenclature of neck dissection may introduce challenges concerning registration for billing and historical comparisons. These issues can be addressed and should not preclude refinements and modifications in the nomenclature.

\section{CONCLUSION}

The evolution of neck dissection from the extremes of the original radical neck dissection to the contemporary superselective neck dissection has exposed many shortcomings in the current AHNS Neck Dissection Classification system. This proposed neck dissection classification system overcomes all these limitations and will facilitate communication around the world with reliable reporting and comparison of outcomes among different surgeons and institu- tions. The next step would be for committees of various head and neck societies worldwide to come together and discuss and debate this proposed classification, recommend improvements, and then adopt a uniform international classification system for use by their respective memberships.

\section{REFERENCES}

1. Ferlito A, Johnson JT, Rinaldo A, et al. European surgeons were the first to perform neck dissection. Laryngoscope 2007;117:797-802.

2. Jawdyński F. Przypadek raka pierwotnego szyi. t.z. raka skrzelowego Volkmann'a. Wycięcie nowotworu wraz z rezekcyją tęetnicy szyjówej wspólnej i zyły szyjowej wewnętrznej. Wyzdrowienie. Gaz Lek 1888;8:530-537.

3. Crile GW. On the surgical treatment of cancer of the head and neck. With a summary of one hundred and twenty-one operations performed upon one hundred and five patients. Trans South Surg Gynecol Assoc 1905;18: 108-127.

4. Martin HE, Del Valle B, Ehrlich H, Cahan WG. Neck dissection. Cancer 1951;4:441-499.

5. Suárez O. The problem of metastasis lymphatic cancer of the larynx and hypopharynx. Rev Otorrinolaringol 1963; 23:83-99. [Article in Spanish].

6. Bocca E. Évidement "fonctionel" du cou dans la thérapie de principe des metastases ganglionnaires du cancer du larynx (Introduction à la présentation d'un film). J Fr Oto-rhinolaryngol 1964;13:721-723.

7. Gavilán Alonso C, Blanco Galdín A, Suárez Nieto C. Certival lymph node function-radical dissection. Surgical anatomy. Technic and results. Acta Otorinolaringol Ibero Am 1972;23:703-817. [Article in Spanish].

8. Byers RM. Third International Conference on Cancer in the Neck - Introduction. In: Johnson JT, Didolkar M, editors. Head and Neck Cancer. Vol III. Amsterdam, The Netherlands: Exerpta Medica; 1993. p 481.

9. Ducic Y, Young L, McIntyre J. Neck dissection: past and present. Minerva Chir 2010;65:45-58.

10. Malone J, Robbins KT. Neck dissection after chemoradiation for carcinoma of the upper aerodigestive tract: indications and complications. Curr Opin Otolaryngol Head Neck Surg 2010;18:89-94.

11. Robbins KT, Shannon K, Vieira F. Superselective neck dissection after chemoradiation: feasibility based on clinical and pathologic comparisons. Arch Otolaryngol Head Neck Surg 2007;133:486-489.

12. Hamoir M, Leemans CR, Dolivet G, Schmitz S, Grégoire V, Andry G. Selective neck dissection in the management of the neck after (chemo)radiotherapy for advanced head and neck cancer. Proposal for a classification update. Head Neck 2010;32:816-819.

13. Suen JY, Goepfert H. Standardization of neck dissection nomenclature. Head Neck Surg 1987;10:75-77. (Editorial).

14. Medina JE. A rational classification of neck dissections. Otolaryngol Head Neck Surg 1989;100:169-176.

15. Robbins KT, Medina JE, Wolfe GT, Levine PA, Sessions RB, Pruet CW. Standardizing neck dissection terminology. Official report of the Academy's Committee for Head and Neck Surgery and Oncology. Arch Otolaryngol Head Neck Surg 1991;117:601-605.

16. Robbins KT, Clayman G, Levine PA, et al. Neck dissection classification update: revisions proposed by the American Head and Neck Society and the American Academy of Otolaryngology-Head and Neck 
Surgery. Arch Otolaryngol Head Neck Surg 2002;128: 751-758.

17. Robbins KT, Shaha AR, Medina JE, et al. Consensus statement on the classification and terminology of neck dissection. Arch Otolaryngol Head Neck Surg 2008;134: 536-538.

18. Pellitteri PK, Robbins KT, Neuman T. Expanded application of selective neck dissection with regard to nodal status. Head Neck 1997;19:260-265.

19. Conley JJ, von Fraenkel PH. Historical aspect of head and neck surgery. Ann Otol 1956;65:643-655.

20. Ferlito A, Rinaldo A. Osvaldo Suárez: often-forgotten father of functional neck dissection (in the non-Spanishspeaking literature). Laryngoscope 2004;114:1177-1178.
21. Skolnik EM, Deutsch EC. Conservative neck dissection. J Laryngol Otol Suppl 1983;8:105.

22. Turkula LD, Woods JE. Limited or selective nodal dissection for malignant melanoma of the head and neck. Am J Surg 1984;148:446-448.

23. Hasegawa Y, Saikawa M, Hayasaki K, et al. A new classification and nomenclature system for neck dissections: a proposal by the Japan Neck Dissection Study Group (JNDSG). Jpn J Head Neck Cancer 2005;31:7178.

24. Committee on Classification of Regional Lymph Nodes of Japan Society of Clinical Oncology. Classification of regional lymph nodes in Japan. Int J Clin Oncol 2003;8:248275 . 